\title{
Socioeconomic Outcome and Quality of Life in Adults after Status Epilepticus: A Multicenter, Longitudinal, Matched Case- Control Analysis from Germany
}

\author{
Lena-Marie Kortland', Susanne Knake1, Felix von Podewils², Felix Rosenow ${ }^{1,3}$ \\ and Adam Strzelczyk ${ }^{1,3 *}$ \\ 'Epilepsy Center Hessen, Philipps-University, Marburg, Germany, ${ }^{2}$ Epilepsy Center Greifswald, Ernst-Moritz-Arndt-University, \\ Greifswald, Germany, ${ }^{3}$ Epilepsy Center Frankfurt Rhine-Main, Goethe-University, Frankfurt am Main, Germany
}

OPEN ACCESS

Edited by:

Batool F. Kirmani,

Texas A\&M Health Science

Center College of Medicine,

United States

Reviewed by:

Fengfei Wang,

Texas A\&M College of Medicine,

United States

Dieter Schmidt,

Epilepsy Research Group, Germany

${ }^{*}$ Correspondence:

Adam Strzelczyk

strzelczyk@med.uni-frankfurt.de

Specialty section:

This article was submitted to

Epilepsy,

a section of the journal

Frontiers in Neurology

Received: 18 August 2017 Accepted: 08 September 2017 Published: 26 September 2017

Citation:

Kortland LM, Knake S, von Podewils $F$, Rosenow $F$ and

Strzelczyk A (2017) Socioeconomic

Outcome and Quality of Life in Adults after Status Epilepticus:

A Multicenter, Longitudinal,

Matched Case-Control

Analysis from Germany.

Front. Neurol. 8:507.

doi: 10.3389/fneur.2017.00507
Background: There is a lack of data concerning socioeconomic outcome and quality of life (QoL) in patients after status epilepticus (SE) in Germany.

Patients and methods: Adult patients treated between 2011 and 2015 due to SE at the university hospitals in Frankfurt, Greifswald, and Marburg were asked to fill out a questionnaire regarding long-term outcome of at least 3 months after discharge. The SE cohort consisted of $25.9 \%$ patients with an acute symptomatic, $42 \%$ with a remote symptomatic and previous epilepsy, $22.2 \%$ with a new-onset remote symptomatic, and 9.9\% with other or unknown etiology. A matched case-control analysis was applied for comparison with patients with drug refractory epilepsy and seizure remission, both not previously affected by SE.

Results: A total of 81 patients (mean age: $58.7 \pm 18.0$ years; $58 \%$ female) participated. A non-refractory course was present in $59.3 \%$, while $27.2 \%$ had a refractory SE (RSE) and $13.6 \%$ had a superrefractory SE (SRSE). Before admission, a favorable modified Rankin Scale (mRS) of 0-3 was found in $82.7 \%$ (67/81), deteriorating to $38.3 \%(31 / 81)$ $(p=0.003)$ at discharge. The majority returned home [51.9\% (42/81)], 32.1\% entered a rehabilitation facility, while $12.3 \%$ were transferred to a nursing home and $3.7 \%$ to another hospital. The overall mRS at follow-up did not change; $61.8 \%(45 / 74)$ reached an $\mathrm{mRS}$ of $0-3$. In RSE and SRSE, the proportion with a favorable mRS increased from $45.5 \%$ at discharge to 70\% at follow-up, while QoL was comparable to a non-refractory SE course. Matched epilepsy controls in seizure remission were treated with a lower mean number of anticonvulsants $(1.3 \pm 0.7)$ compared to controls with drug refractory epilepsy $(1.9 \pm 0.8 ; p<0.001)$ or SE $(1.9 \pm 1.1 ; p<0.001)$. A major depression was found in $32.8 \%$ of patients with SE and in $36.8 \%$ of drug refractory epilepsy, but only in $20.3 \%$ of patients in seizure remission. QoL was reduced in all categories (QOLIE-31) in SE patients in comparison with patients in seizure remission, but was comparable to patients with drug refractory epilepsy.

Discussion: Patients after SE show substantial impairments in their QoL and daily life activities. However, in the long term, patients with RSE and SRSE had a relatively 
favorable outcome comparable to that of patients with a non-refractory SE course. This underlines the need for efficient therapeutic options in SE.

Keywords: epilepsy, seizure, anticonvulsants, morbidity, mortality

\section{INTRODUCTION}

Status epilepticus (SE) presents as a major neurological emergency and is associated with a substantial burden on individuals and society (1-3). Prolonged inpatient treatment and neurological sequelae due to SE lead to substantial direct and indirect costs and result in reduced quality of life (QoL). Rehabilitation and informal care are often necessary following discharge from acute treatment and might result in further costs. Studies on outcome show a substantial portion of patients who are discharged with a neurologic deficit, while overall hospital mortality is about 15-20\%. Both SE related morbidity and mortality increase with a refractory course and prolonged inpatient treatment (4-6). Prehospital and in-hospital treatment strategies aim at a timely cessation of seizure activity and consist of benzodiazepines, intravenous anticonvulsants, and anesthetic drugs in selected cases (7).

Given the reduced QoL and increased rate of depression in patients with drug refractory epilepsy, as proven by several studies (8-11), patients with SE are very likely to suffer from decreased QoL and mood disorders. However, there is a paucity of data concerning socioeconomic outcome and QoL in patients after an SE, especially as there is no study on this topic from Germany.

Thus, the objective of this multicenter study is to determine the outcome, resource utilization, and QoL indicators following an episode of SE. For comparison, patients suffering from epilepsy who had never previously experienced an episode of SE were matched by age and gender: we matched two groups, one with a drug refractory epilepsy (DRE) and one with epilepsy patients in seizure remission (SRE) for more than 1 year as they show distinct outcomes regarding QoL, health resource utilization, and mood disorders.

\section{PATIENTS AND METHODS}

\section{Study Settings and Design}

This longitudinal study on outcome, QoL, and resource utilization was performed by means of a bottom-up approach from the perspective of the statutory health insurer at the university hospitals in Frankfurt am Main, Greifswald, and Marburg. The study was granted approval by the local ethics committees and registered at the German Clinical Trials Register (DRKS00008718). The Strengthening the Reporting of Observational Studies in Epidemiology (STROBE) guidelines were followed (12).

Adult patients of 18 years or older treated due to SE at the participating university hospitals during the 5-year study period of 2011-2015 were asked to fill out a questionnaire regarding long-term outcome for at least 3 months after discharge. Overall, 669 patients were treated due to SE during the study period with an average in-hospital mortality of $18.8 \%(n=126)$. Therefore, responder rate was $15 \%$ regarding 81 of 543 survivors. The questionnaire was validated for use in people with epilepsy $(13,14)$. Patients with SE received standard care with no intervention due to the study, and a decision for rehabilitation after SE was at the discretion of the treating physician. An operational definition consistent with ILAE guidelines was adopted that defines convulsive $\mathrm{SE}$ as $\geq 5$ min of continuous seizure or two or more discrete seizures, between which there is an incomplete recovery $(15,16)$. In case of focal SE or absence SE, the definition encompassed at least $5 \mathrm{~min}$ of seizure duration; however, none of the patients were identified with a focal SE or absence SE below duration of $20 \mathrm{~min}$ (1). Refractory SE (RSE) was defined as recurrent seizure activity despite two appropriately selected and dosed antiepileptic drugs, including benzodiazepine, and superrefractory SE (SRSE) was referred to as a SE that continues or recurs $24 \mathrm{~h}$ or more after the initiation of treatment with anesthetic drugs, including cases in which seizure control is attained after induction of anesthesia, but recurs on weaning the patient off the anesthetic agent $(4,17,18)$. Patients were assigned to four major groups based on etiology and onset of SE with (1) acute symptomatic SE, due to an acute brain injury as defined by the ILAE (19); (2) new-onset, remote symptomatic SE, with no history of epilepsy or SE; (3) remote symptomatic SE, with history of epilepsy or SE; and (4) other etiologies, such as idiopathic generalized epilepsy or progressive symptomatic causes. The epilepsy diagnosis was based on the definitions proposed by the ILAE and the International Bureau for Epilepsy (20). Patients were excluded if the diagnosis of SE could not be unequivocally determined, or if SE was due to hypoxia after cardiopulmonary resuscitation.

We employed a matched case-control analysis to compare the SE group with two control groups of epilepsy patients, either with drug refractory epilepsy (DRE) or in seizure remission (SRE) for more than 1 year. None of the patients from the epilepsy control groups suffered from an SE during their lifetime. Patients were matched by age and gender. The distribution of age and gender did not differ significantly across the groups, except for SRE patients, who were, in mean, 2 years younger than patients in the SE group.

\section{Instruments}

To analyze the health-related QoL, we used scales, such as Quality of Life in Epilepsy Inventory (QOLIE-31) (21), Neurological Disorders Depression Inventory for Epilepsy (NDDI-E) (22), A-B neuropsychological assessment schedule (ABNAS, originally the A-B neurotoxicity scale) (23), Liverpool Adverse Events Profile (LAEP) (24), and the EuroQol questionnaire (EQ-5D) (25). Measures of severity of illness and long-term outcome included the modified Rankin Scale (mRS) (26) on admission, discharge, and follow-up. Healthcare resource utilization is reported as use of inpatient, outpatient, rehabilitation, and anticonvulsive treatment. For cost unit data and details of evaluation, please refer to previous publications $(27,28)$.

\section{Data Entry and Statistical Analysis}

Statistical analyses were performed using IBM SPSS Statistics, version 22.0 (IBM Corp., Armonk, NY, USA). Most data are 
presented as percentage or mean $\pm \mathrm{SD}$ and as minimum and maximum. Comparisons between groups were accomplished using adequate parametric and non-parametric tests. Since the study was planned to have an explorative nature, no further adjustment for multiple testing was performed.

\section{RESULTS}

\section{Characteristics of Patients with SE}

During the 5-year study period, a total of 81 patients (mean age: $58.7 \pm 18.0$ years, range: $21-97$ years; $58.0 \%$ female) participated in the study. An acute symptomatic etiology was present in $25.9 \%$ $(n=21)$, a remote symptomatic SE was attributed in $22.2 \%$ ( $n=18)$ with new-onset SE, and in $42.0 \%(n=34)$ of patients with history of epilepsy, other or unknown etiologies were seen in $9.9 \%(\mathrm{n}=8)$. Of these cases, $59.3 \%(n=48)$ had a non-RSE, $27.2 \%(n=22)$ an RSE, and $13.6 \%(n=11)$ had an SRSE. Details of clinical or socioeconomic characteristics and QoL at least 3 months after SE are provided in Table 1.

Before admission, a favorable mRS of $0-3$ was present in $82.7 \%$ $(n=67)$, while an unfavorable mRS of $4-5$ was seen in $17.3 \%$ $(n=14)$ of the SE population. On discharge, mRS decreased significantly with 31 patients $(38.3 \%, p=0.003)$ rated at an unfavorable $\mathrm{mRS}$ of $4-5$. The mRS at follow-up did not differ from the one at discharge; $60.8 \%(45 / 74)$ presented an mRS of $0-3$ and $39.2 \%(29 / 74)$ an mRS of $4-5$ (Figure 1); seven patients did not report their mRS on follow-up. Regarding RSE and SRSE, a favorable mRS of $0-3$ was present in $45.5 \%$ at discharge and increased to $70 \%$ at follow-up.

At discharge, the majority returned home $(51.9 \%, n=42)$, $32.1 \%(n=26)$ entered a rehabilitation facility, $12.3 \%(n=10)$ were transferred into a nursing home, and 3.7\% $(n=3)$ to another hospital. At the time of follow-up, 21 patients (25.9\%) lived at home without any help, 43 (54\%) depended on aid of their families, and partners or of ambulatory nursing care, while 16 patients (19.8\%) lived in a nursing home. A care level (Pflegestufe) was attributed to $56.8 \%$ and a grade of disability to $79 \%$ of the SE patients. Only 9 of 49 patients of working age (18.4\%) had been employed at follow-up.

Regarding healthcare resource utilization within the last 3 months, an ambulance transport to hospital was necessary in $13.2 \%$. The mean number of outpatient consultations due to epilepsy amounted to $3.1 \pm 3.3$ (range 1-17). Overall, $22.5 \%$ ( $n=18 / 81$ ) of the SE patients were hospitalized due to epilepsy for a mean of 6.8 days within the last 3 months. Patients were in need of ancillary therapies, such as physiotherapy, occupational therapy, or speech therapy, with a mean number of $22.1 \pm 18.3$ (range 1-80) sessions within the previous 3 months. The number of AEDs did not differ at follow-up compared to discharge (see Figure 2).

The evaluation of QoL using the EQ-5D-Index showed $0.57 \pm 0.36$ on average $(0=$ death to $1=$ full health $)$. Most of the patients showed impairments due to side effects of anticonvulsants; the mean ABNAS score amounted to $34.9 \pm 20.8$ and $73.6 \%$ of the patients reported a high score (ABNAS 0-99, $99=$ the worst score, $>15=$ high score, and $\leq 15=$ low score) (23).
TABLE 1 | Socioeconomic and clinical characteristics in patients with SE provided for all patients $(n=81)$ and according to a non-RSE $(n=48)$ and RSE or SRSE course $(n=33)$.

\begin{tabular}{|c|c|c|c|c|}
\hline & $\begin{array}{l}\text { All patients } \\
\text { with SE } \\
(n=81)\end{array}$ & $\begin{array}{c}\text { Non-RSE } \\
(n=48)\end{array}$ & $\begin{array}{c}\text { RSE/SRSE } \\
(n=33)\end{array}$ & $p$ Value $^{a}$ \\
\hline \multicolumn{5}{|l|}{ Age (years) at admission } \\
\hline Mean \pm SD & $58.7 \pm 18.0$ & $61.8 \pm 16.8$ & $54.2 \pm 18.9$ & 0.063 \\
\hline Range & 21-97 & 23-97 & 21-80 & \\
\hline Sex & $\%(n)$ & $\%(n)$ & $\%(n)$ & \\
\hline Male & $42.0(34)$ & $35.4(17)$ & $51.5(17)$ & 0.225 \\
\hline Female & $58.0(47)$ & $64.6(31)$ & $48.5(16)$ & \\
\hline Etiology & $\%(n)$ & $\%(n)$ & $\%(n)$ & \\
\hline Acute symptomatic & $25.9(21)$ & $16.7(8)$ & $39.4(13)$ & 0.021 \\
\hline Remote symptomatic & $42.0(34)$ & $43.8(21)$ & $39.4(13)$ & $\begin{array}{l}\text { (Acute } \\
\text { vs non- } \\
\text { acute) }\end{array}$ \\
\hline New onset SE & $22.2(18)$ & $27.1(13)$ & $15.2(5)$ & \\
\hline Other or unknown & $9.9(8)$ & $12.5(6)$ & $6.1(2)$ & \\
\hline mRS at admission & $\%(n)$ & $\%(n)$ & $\%(n)$ & \\
\hline mRS 0-3 & $82.7(67)$ & $81.3(39)$ & $84.8(28)$ & 0.673 \\
\hline mRS 4-5 & $17.3(14)$ & $18.8(9)$ & $15.2(5)$ & \\
\hline $\mathrm{mRS}$ at discharge & $\%(n)$ & $\%(n)$ & $\%(n)$ & \\
\hline mRS 0-3 & $61.7(50)$ & $72.9(35)$ & $45.5(15)$ & 0.012 \\
\hline mRS 4-5 & $38.3(31)$ & $27.1(13)$ & $54.5(18)$ & \\
\hline mRS at follow-up & $\%(n)$ & $\%(n)$ & $\%(n)$ & \\
\hline mRS 0-3 & $60.8(45)$ & $54.5(24)$ & $70.0(21)$ & 0.180 \\
\hline mRS 4-5 & $39.2(29)$ & $45.5(20)$ & $30.0(9)$ & \\
\hline Discharge destination & $\%(n)$ & $\%(n)$ & $\%(n)$ & \\
\hline Home & $51.9(42)$ & $64.6(31)$ & $33.3(11)$ & 0.013 \\
\hline Rehabilitation & $32.1(26)$ & $16.7(8)$ & $54.5(18)$ & $\begin{array}{c}\text { (home } \\
\text { vs other) }\end{array}$ \\
\hline Other hospital & 3.7 (3) & $2.1(1)$ & $6.1(2)$ & \\
\hline Nursing home & $12.3(10)$ & $16.7(8)$ & $6.1(2)$ & \\
\hline Living situation & $\%(n)$ & $\%(n)$ & $\%(n)$ & \\
\hline At home without help & $25.9(21)$ & $27.1(13)$ & $24.2(8)$ & 0.732 \\
\hline $\begin{array}{l}\text { At home with help } \\
\text { (family, nursing, etc.) }\end{array}$ & $54.0(43)$ & $47.9(23)$ & $60.6(20)$ & \\
\hline Nursing home & $19.8(16)$ & $22.9(11)$ & $15.2(5)$ & \\
\hline n.a. & (1) & (1) & & \\
\hline Care level & $\%(n)$ & $\%(n)$ & $\%(n)$ & \\
\hline None & $33.3(27)$ & $33.3(16)$ & $33.3(11)$ & 0.947 \\
\hline $\begin{array}{l}\text { None, but in need } \\
\text { of care }\end{array}$ & $8.6(7)$ & $10.4(5)$ & $6.1(2)$ & \\
\hline $\begin{array}{l}\text { Care level existing } \\
\text { n.a. }\end{array}$ & $\begin{array}{c}56.8(46) \\
(1)\end{array}$ & $\begin{array}{c}54.2(26) \\
(1)\end{array}$ & $60.6(20)$ & \\
\hline Grade of disability & $\%(n)$ & $\%(n)$ & $\%(n)$ & \\
\hline Yes & $79.0(64)$ & $79.2(38)$ & $78.8(26)$ & 0.820 \\
\hline None & $19.8(16)$ & $18.8(9)$ & $21.2(7)$ & \\
\hline n.a. & (1) & (1) & & \\
\hline $\begin{array}{l}\text { Number of AEDs at } \\
\text { discharge }\end{array}$ & $\%(n)$ & $\%(n)$ & $\%(n)$ & \\
\hline 0 & $1.2(1)$ & - & $3.0(1)$ & \\
\hline 1 & $33.3(27)$ & $43.8(21)$ & $18.2(6)$ & \\
\hline 2 & $32.1(26)$ & $35.4(17)$ & $27.3(9)$ & \\
\hline$\geq 3$ & $33.3(27)$ & $20.8(10)$ & $51.5(17)$ & \\
\hline Total (mean \pm SD) & $2.1 \pm 1.0$ & $1.8 \pm 0.9$ & $2.5 \pm 1.1$ & 0.007 \\
\hline $\begin{array}{l}\text { Number of AEDs at } \\
\text { follow-up }\end{array}$ & $\%(n)$ & $\%(n)$ & $\%(n)$ & \\
\hline 0 & $4.2(3)$ & $2.4(1)$ & $6.7(2)$ & \\
\hline 1 & $40.3(29)$ & $50.0(21)$ & 26.7 (8) & \\
\hline 2 & $19.4(14)$ & $23.8(10)$ & $13.3(4)$ & \\
\hline$\geq 3$ & $36.1(26)$ & $23.8(10)$ & $53.3(16)$ & \\
\hline Total (mean \pm SD) & $1.9 \pm 1.1$ & $1.8 \pm 1.0$ & $2.2 \pm 1.1$ & 0.113 \\
\hline
\end{tabular}


TABLE $1 \mid$ Continued

$\begin{array}{cccc}\text { All patients } & \text { Non-RSE } & \text { RSE/SRSE } & p \text { Value }^{a} \\ \text { with SE } & (n=48) & (n=33) & \\ (n=81) & & \end{array}$

\begin{tabular}{lcccc}
\hline \multicolumn{5}{l}{ Healthcare resource utilization within the last 3 months } \\
Inpatient treatment due & $\%(n)$ & $\%(n)$ & $\%(n)$ & \\
to epilepsy & & & & \\
Yes & $22.2(18)$ & $17.0(8)$ & $30.3(10)$ & 0.146 \\
$\quad$ None & $77.7(63)$ & $83.0(40)$ & $69.7(23)$ & \\
Outpatient hospital & $\%(n)$ & $\%(n)$ & $\%(n)$ & \\
treatment due to & & & & \\
epilepsy & & & & \\
Yes & $14.3(11)$ & $11.1(5)$ & $18.8(6)$ & 0.316 \\
None & $85.7(70)$ & $88.9(43)$ & $81.3(27)$ & \\
NDDI-E & $\%(n)$ & $\%(n)$ & $\%(n)$ & \\
Major depression & $32.8(19)$ & $30.3(10)$ & $36.0(9)$ & 0.647 \\
(Score >15) & & & & \\
No major depression & $67.2(39)$ & $69.7(23)$ & $64.0(16)$ & \\
(Score $\leq 15)$ & & & & \\
ABNAS & & & & \\
Total (mean \pm SD) & $34.9 \pm 20.8$ & $34.6 \pm 20.1$ & $35.2 \pm 22.0$ & 0.351 \\
Range & $0-72$ & $3-71$ & $0-72$ & \\
LAEP & & & & \\
Total (mean \pm SD) & $41.9 \pm 10.4$ & $41.5 \pm 10.3$ & $42.3 \pm 10.8$ & 0.997 \\
Range & $14-63$ & $20-62$ & $14-63$ & \\
QOLIE-31 & & & & \\
Overall T (mean \pm SD) & $43.5 \pm 13.7$ & $44.2 \pm 13.9$ & $42.5 \pm 13.6$ & 0.870 \\
Range & $11-73$ & $11-73$ & $16-66$ & \\
VAS (mean \pm SD) & $48.3 \pm 24.5$ & $49.2 \pm 22.7$ & $47.2 \pm 27.0$ & 0.618 \\
\hline
\end{tabular}

aComparison between non-RSE and RSE/SRSE.

SE, status epilepticus; RSE, refractory SE; SRSE, superrefractory SE; mRS, modified Rankin Scale; AEDs, antiepileptic drugs; NIDDI-E, Neurological Disorders Depression inventory for Epilepsy; LAEP, Liverpool Adverse Events Profile; QOLIE, Quality of Life in Epilepsy Inventory; VAS, visual analog scale; ABNAS, A-B neuropsychological assessment schedule.
Table 1 presents the socioeconomic characteristics and QoL in relation to the severity of SE. Admissions were more likely due to an acute symptomatic etiology in patients with RSE or SRSE (39.4\%) than with a non-refractory course $(16.7 \%, p=0.021)$. Furthermore, the course of SE had a significant impact on the degree of disability, as measured by $\mathrm{mRS}$ at discharge [mRS 0-3 in $72.9 \%(35 / 48)$ vs $45.5 \%(15 / 33) ; p=0.012]$. Patients with RSE and SRSE were discharged with more AEDs $[2.5 \pm 1.1$ (mean \pm SD) vs $1.8 \pm 0.9 ; p=0.007]$, while this difference was not detectable at follow-up $(p=0.113)$. Patients with non-RSE were more frequently discharged home (64.6 vs $33.3 \%$; $p=0.013$ ), while more patients with RSE or SRSE were transferred into a rehabilitation center ( 54.5 vs $16.7 \%$; $p<0.001$ ). Concerning the QoL, patients after an RSE or SRSE achieved the same outcome as patients with a non-refractory course, as measured by NDDI-E, ABNAS, LAEP, QOLIE-31, or VAS.

\section{Comparison of QoL between Patients after SE and Patients with Drug Refractory Epilepsy and in Seizure Remission}

For each patient after SE, one patient with DRE and one with SRE were matched by age and gender. The mean length of epilepsy amounted to $19.9 \pm 17.6$ years in DRE and to $17.0 \pm 16.0$ years in SRE. SE patients had a significantly shorter length of epilepsy $(9.3 \pm 14.2$ years, $p<0.001 \mathrm{DRE}$ and $p=0.001 \mathrm{SRE})$ at follow-up.

Table 2 shows the socioeconomic and clinical characteristics and QoL of SE patients at follow-up compared to patients with DRE and SRE. In the two control groups, significantly more patients lived at home independently than in the SE group

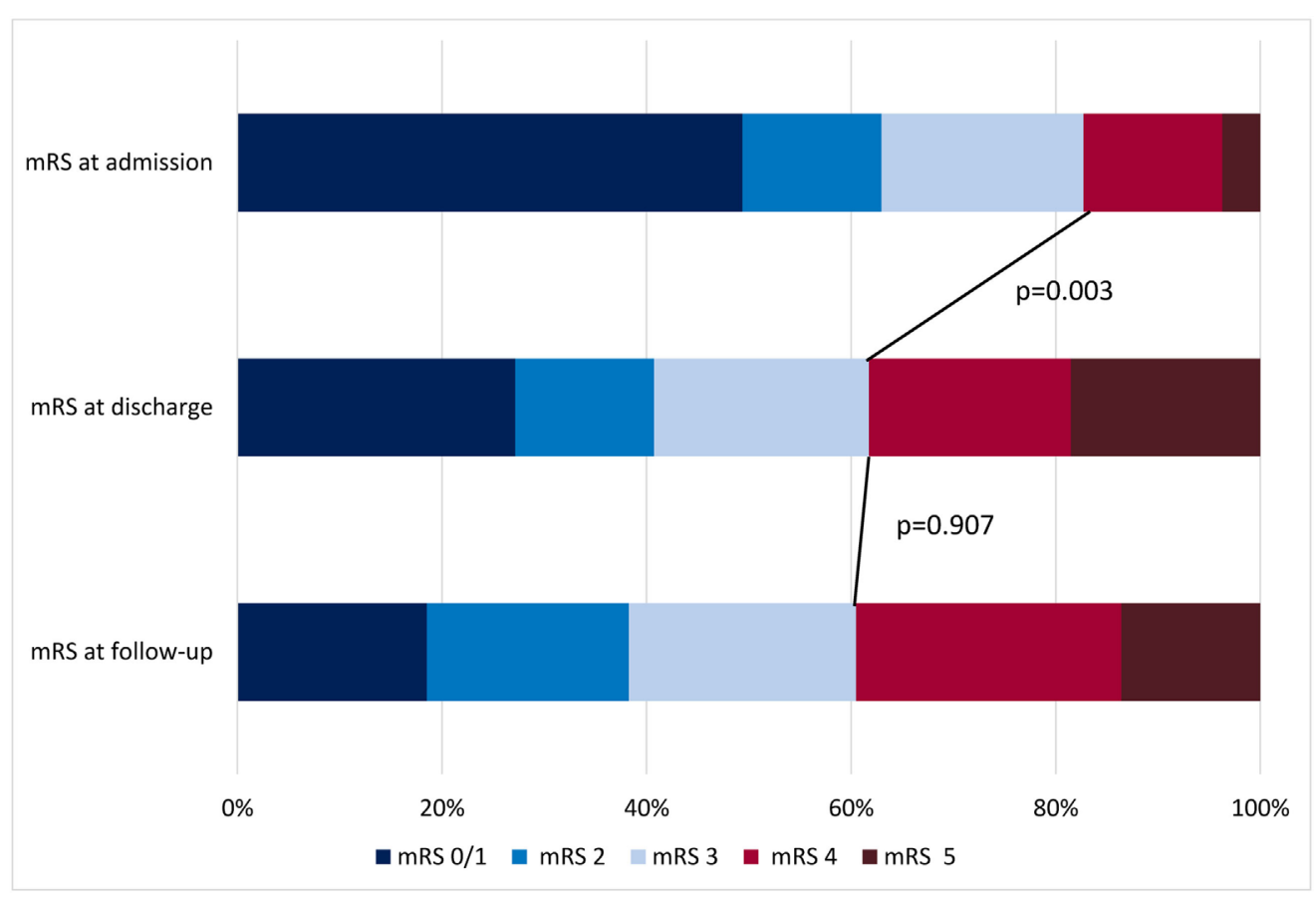

FIGURE 1 | Modified Rankin Scale (mRS) at admission, discharge, and follow-up in patients with status epilepticus. 


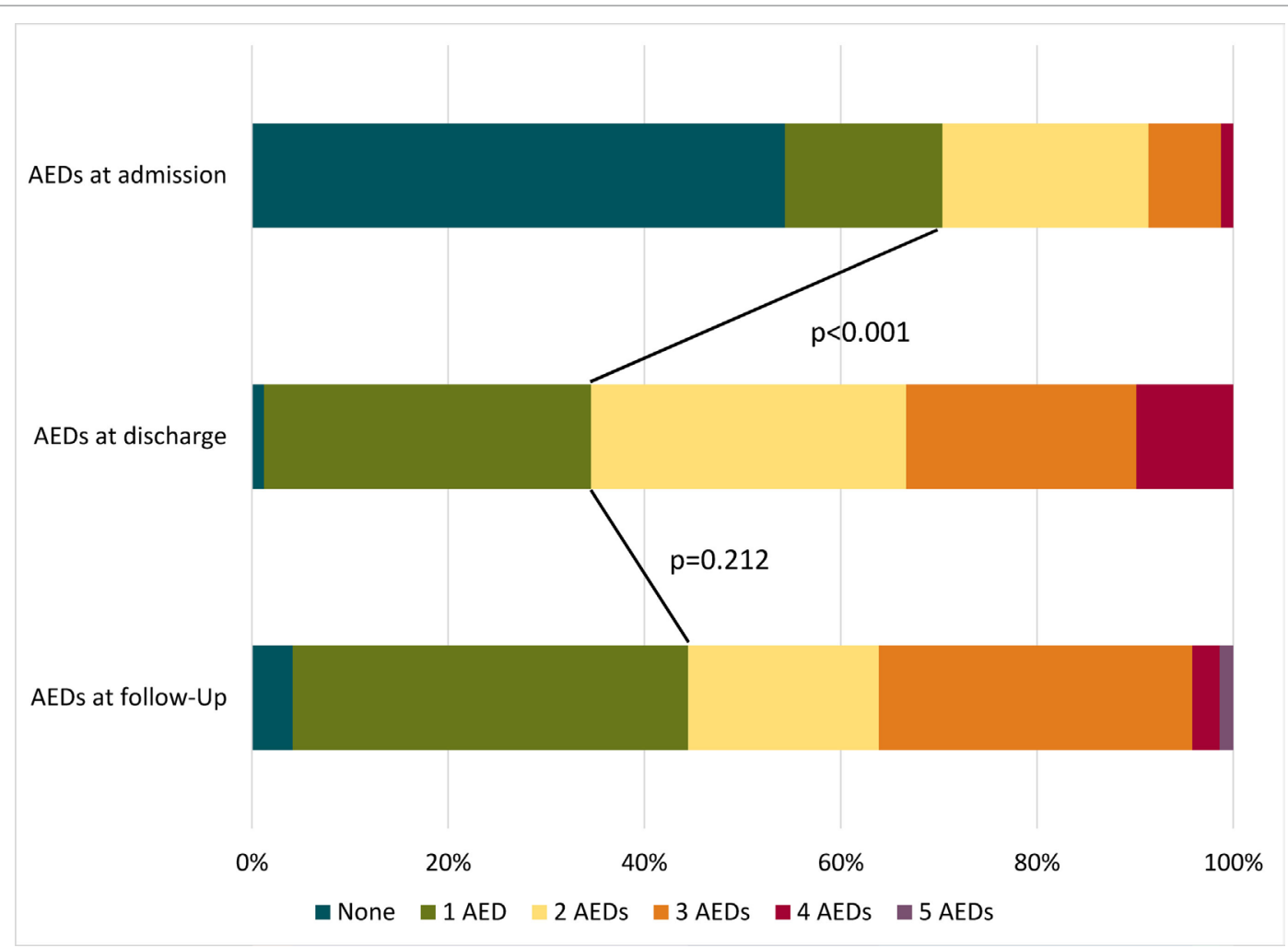

FIGURE 2 | Number of used anticonvulsants at admission, discharge, and follow-up in patients with status epilepticus. AEDs, antiepileptic drugs.

(SE: $25.9 \%$; DRE: $46.3 \%$; $p=0.008$, SRE: $64.6 \% ; p<0.001$ ), in particular, in the cohort with SRE, no patient lived in a nursing home. Concerning marital status, $70.3 \%$ of patients with SRE were married in comparison to $55.6 \%(p=0.048)$ of patients in the SE cohort. The mRS at follow-up documented a better state of health for both control groups (mRS 0-3: DRE $98.8 \%$, SRE 97.5\%) in comparison to the SE group (mRS 0-3 in $60.8 \% ; p<0.001$ each). Regarding epilepsy-related healthcare resource utilization, about $22.2 \%(n=18)$ of the SE patients were treated in a hospital, whereas fewer patients with drug refractory epilepsy $(11.1 \% ; n=9, p=0.057)$ and with SRE (1.2\%; $n=1, p<0.001)$ were hospitalized due to epilepsy within the last 3 months. Mean length of stay amounted to $6.8 \pm 5.9$ days (range $1-20$ ) for SE, $7.0 \pm 5.2$ days (range $1-18$ ) for DRE, and 7.0 days for SRE. An outpatient hospital treatment due to epilepsy was necessary for $14.3 \%$ patients with SE, $23.8 \%$ of patients with DRE, and $7.9 \%$ of patients in SRE. Patients in SRE were treated with a mean number of $1.3 \pm 0.7$ anticonvulsants (AEDs) and with significantly fewer AEDs than those with drug refractory epilepsy $(1.9 \pm 0.8 ; p<0.001)$ or SE $(1.9 \pm 1.1 ; p<0.001)$.

A major depression, as indicated by NDDI-E, was found in nearly one-third of patients with SE (32.8\%) and DRE (36.8\%), but only in $20.3 \%$ of patients with SRE. Side effects intensity evaluated by the LAEP score was $41.9 \pm 10.4$ in SE patients, $40.5 \pm 11.8$ in DRE patients, and lower in SRE patients $(37.0 \pm 11.8 ; p=0.011)$.
A better QoL, measured by QOLIE-31 and VAS, was seen for patients in SRE in all categories compared to patients after SE. Regarding the subcategory QoL, both patients with DRE $(p=0.013)$ and SRE $(p<0.001)$ scored better than patients after SE; for details, please refer to Table 2.

\section{DISCUSSION}

This study on QoL and socioeconomic outcome after an episode of SE is the first comprehensive evaluation to address sequelae and outcome of adult patients with SE and compare them with matched epilepsy controls with a drug refractory course or in SRE. We can show that patients with RSE and SRSE had a deterioration in neurological functions at discharge, which can be set off at follow-up. Furthermore, patients after RSE and SRSE may achieve an equivalent QoL compared to patients after a non-RSE. Despite persistent and increased neurological deficits in patients after SE, these patients may achieve similar QoL values to patients with DRE who have no neurological deficits. However, QoL was reduced in all subcategories of QOLIE-31 when compared to patients in SRE.

Our findings underline the need for an efficient therapy of RSE and SRSE, as these patients will, on average, achieve outcomes comparable to patients with a non-RSE and patients with DRE. That is remarkable as these patients are suffering from persisting neurological deficits, as measured by mRS, and show 
TABLE 2 | Socioeconomic and clinical characteristics of patients with SE in comparison to matched epilepsy patients with drug refractory course and in seizure remission ( $n=81$ in each group).

\begin{tabular}{|c|c|c|c|c|}
\hline & SE $(n=81)$ & $\begin{array}{l}\text { Drug-resistant epilepsy } \\
\qquad(n=81)\end{array}$ & $\begin{array}{l}\text { Epilepsy in SRE >1 year } \\
\qquad(n=81)\end{array}$ & $p$ Value \\
\hline \multicolumn{5}{|l|}{ Age (years) at survey } \\
\hline Mean $\pm S D$ & $58.7 \pm 18.0$ & $57.3 \pm 15.6$ & $56.2 \pm 14.0$ & 0.082 (SE vs DRE) \\
\hline Range & 21-97 & 21-94 & 20-87 & 0.001 (SE vs SRE) \\
\hline Sex & $\%(n)$ & $\%(n)$ & $\%(n)$ & \\
\hline Male & $42.0(34)$ & $42.0(34)$ & $42.0(34)$ & 1.0 \\
\hline Female & $58.0(47)$ & $58.0(47)$ & $58.0(47)$ & \\
\hline Marital status & $\%(n)$ & $\%(n)$ & $\%(n)$ & \\
\hline Married or with partner & $55.6(45)$ & $64.2(52)$ & $70.4(57)$ & 0.302 (SE vs DRE) \\
\hline Divorced or in separation & $6.2(5)$ & $7.4(6)$ & $9.9(8)$ & 0.048 (SE vs SRE) \\
\hline Living with family/relatives & $7.4(6)$ & $11.1(9)$ & $12.3(10)$ & \\
\hline Widowed & $29.6(24)$ & $17.3(14)$ & $6.2(5)$ & \\
\hline n.a. & (1) & & (1) & \\
\hline Living situation & $\%(n)$ & $\%(n)$ & $\%(n)$ & \\
\hline At home without help & $25.9(21)$ & $45.7(37)$ & $62.9(51)$ & 0.008 (SE vs DRE) \\
\hline At home with help (family, nursing service) & $54.0(43)$ & $50.6(41)$ & $34.6(28)$ & $<0.001$ (SE vs SRE) \\
\hline Nursing home & $19.8(16)$ & $2.5(2)$ & - & \\
\hline n.a. & (1) & (1) & $2.5(2)$ & \\
\hline mRS at follow-up & $\%(n)$ & $\%(n)$ & $\%(n)$ & \\
\hline mRS 0-3 & $60.8(45)$ & $98.8(80)$ & $97.5(79)$ & $<0.001$ each \\
\hline mRS 4-5 & $39.2(29)$ & $1.2(1)$ & $2.5(2)$ & \\
\hline Number of AEDs at follow-up & $\%(n)$ & $\%(n)$ & $\%(n)$ & \\
\hline 0 & $4.2(3)$ & - & $4.9(4)$ & \\
\hline 1 & $40.3(29)$ & $40.7(33)$ & $65.4(53)$ & \\
\hline 2 & $19.4(14)$ & $35.8(29)$ & $25.9(21)$ & \\
\hline$\geq 3$ & $36.1(26)$ & $23.5(19)$ & 3.7 (3) & \\
\hline Number of AEDs (mean \pm SD) & $1.9 \pm 1.1$ & $1.9 \pm 0.8$ & $1.3 \pm 0.7$ & 0.632 (SE vs DRE); <0.001 (SE vs SRE) \\
\hline \multicolumn{5}{|c|}{ Healthcare resource utilization within the last 3 months } \\
\hline Inpatient treatment due to epilepsy & $\%(n)$ & $\%(n)$ & $\%(n)$ & \\
\hline Yes & $22.2(18)$ & $11.1(9)$ & $1.2(1)$ & 0.057 (SE vs DRE) \\
\hline None & $77.7(63)$ & $88.9(72)$ & $98.8(80)$ & $<0.001$ (SE vs SRE) \\
\hline Length of stay (mean \pm SD) & $6.8 \pm 5.9$ & $7.0 \pm 5.2$ & 7.0 & \\
\hline Outpatient hospital treatment due to epilepsy & $\%(n)$ & $\%(n)$ & $\%(n)$ & \\
\hline Yes & $14.3(11)$ & $23.8(19)$ & $7.9(6)$ & 0.105 (SE vs DRE) \\
\hline None & $85.7(70)$ & $76.3(62)$ & $92.1(75)$ & 0.2 (SE vs SRE) \\
\hline NDDI-E & $\%(n)$ & $\%(n)$ & $\%(n)$ & \\
\hline Major depression (>15 points) & $32.8(19)$ & $36.8(21)$ & $20.3(12)$ & 0.79 (SE vs DRE) \\
\hline No major depression ( $\leq 15$ points) & $67.2(39)$ & $63.2(36)$ & $79.7(47)$ & 0.128 (SE vs SRE) \\
\hline LAEP & $\%(n)$ & $\%(n)$ & $\%(n)$ & \\
\hline Total score (mean \pm SD) & $41.9 \pm 10.4$ & $40.5 \pm 11.8$ & $37.0 \pm 11.8$ & 0.375 (SE vs DRE) \\
\hline Range & $14-63$ & 19-69 & $19-45$ & 0.011 (SE vs SRE) \\
\hline QOLIE-31 (1-100, 100 best QoL) & $\%(n)$ & $\%(n)$ & $\%(n)$ & \\
\hline Overall T & $43.5 \pm 13.7$ & $44.8 \pm 12.8$ & $51.8 \pm 12.5$ & 0.698 (SE vs DRE); <0.001 (SE vs SRE) \\
\hline Quality of Life T & $41.7 \pm 11.5$ & $46.6 \pm 9.7$ & $50.2 \pm 11.2$ & 0.013 (SE vs DRE); <0.001 (SE vs SRE) \\
\hline Seizure Worry $T$ & $51.3 \pm 12.3$ & $48.9 \pm 10.5$ & $56.0 \pm 9.7$ & 0.084 (SE vs DRE); 0.042 (SE vs SRE) \\
\hline Emotional Well-Being T & $43.8 \pm 11.2$ & $46.3 \pm 10.7$ & $49.4 \pm 10.8$ & 0.296 (SE vs DRE); 0.009 (SE vs SRE) \\
\hline Energy-Fatigue T & $43.6 \pm 9.2$ & $46.3 \pm 9.8$ & $49.6 \pm 10.1$ & 0.114 (SE vs DRE); 0.002 (SE vs SRE) \\
\hline Cognitive Functioning $\mathrm{T}$ & $45.8 \pm 12.6$ & $46.8 \pm 12.0$ & $50.6 \pm 11.9$ & 0.832 (SE vs DRE); 0.011 (SE vs SRE) \\
\hline Medication Effects T & $49.0 \pm 10.7$ & $50.8 \pm 9.6$ & $53.8 \pm 9.3$ & 0.328 (SE vs DRE); 0.011 (SE vs SRE) \\
\hline Social Functioning $T$ & $44.3 \pm 11.8$ & $45.2 \pm 10.5$ & $52.0 \pm 10.4$ & 0.909 (SE vs DRE); <0.001 (SE vs SRE) \\
\hline VAS $($ mean $\pm S D)$ & $48.3 \pm 24.5$ & $55.3 \pm 22.9$ & $65.3 \pm 22.1$ & $\begin{array}{c}0.269 \text { (SE vs DRE) } \\
<0.001 \text { (SE vs SRE) }\end{array}$ \\
\hline
\end{tabular}

AEDs, antiepileptic drugs; SE, status epilepticus; DRE, drug refractory epilepsy; mRS, modified Rankin Scale; NIDDI-E, Neurological Disorders Depression Inventory for Epilepsy; LAEP, Liverpool Adverse Events Profile; QOLIE, Quality of Life in Epilepsy Inventory; VAS, visual analog scale; SRE, seizure remission.

an increased need for assistance in daily activities. Furthermore, patients with RSE and SRSE improve in neurological outcome over time. This is in line with previous findings, as reported by Lai et al. (29). They reported functional outcome using the mRS in patients with prolonged RSE on admission, discharge, and 1 year after discharge. In their cohort, a favorable outcome of
mRS $0-3$ increased from $11.5 \%$ of patients at discharge to $17.1 \%$ of patients at follow-up (29). Ferlisi and Shorvon reported on long-term outcomes of RSE and SRSE, providing mortality rates and data on neurologic defects in 596 cases (4). Overall, $35 \%$ of the patients were able to return to baseline, while $13 \%$ suffered a severe neurologic deficit, a further $13 \%$ had a mild 
neurologic deficit and $4 \%$ had an undefined neurologic deficit. Mortality accumulated to $35 \%$ (4). The preliminary report of the global audit from 44 countries on treatment of RSE and SRSE (30) showed a favorable outcome with an mRS of $0-3$ in $36 \%$ of the patients at discharge $(26.6 \%=\mathrm{mRS} 0-2 ; 9.4 \%=\mathrm{mRS}$ $3)$, which improved to $63.8 \%$ at follow-up $(42.6 \%=$ mRS $0-2$; $21.3 \%=\mathrm{mRS} 3$ ). The follow-up was available for 108 patients with an obvious selection bias, as noted by the authors.

A retrospective study from India used the Glasgow Outcome Scale (GOS) to describe outcome. They reported that SRSE had a worse outcome after 6 months in comparison with RSE (33.3 vs $57.1 \% ; p=0.055)$ and non-RSE (33.3 vs $79.1 \%$; $p<0.0001)$ (31). These findings are well explained by encephalitis as the main underlying etiology in SRSE cases reported from India, an etiology that is independently associated with a poor outcome.

Sutter et al. reported on identification of predictors for outcome involving clinical features such as age, history of prior seizures or epilepsy, SE etiology, level of consciousness, and seizure type at SE onset (6). Determination of predictors from our study is hindered by the limited sample size. However, overall mortality rates of the overall SE group and outcome measures (mRS or GOS) are in line with previous publications $(4,5,29,31)$.

Patients after SE achieved QoL scores comparable to patients with DRE who had never suffered from SE. Given the neurological deficits in the SE group, these seem rather surprising. Strong determinants of reduced QoL in DRE are depression and anxiety, as shown by multiple studies $(9,32,33)$. Furthermore, tolerability and efficacy of AEDs, employment, seizure frequency and semiology, and comorbidities will influence some aspects of QoL in DRE (9, 32-35). These factors are also present in patients after SE, e.g., depression in one-third of our SE cohort, and should be kept in mind during rehabilitation and further outpatient treatment. Use of inpatient and outpatient services after SE remains high, showing the ongoing need for neurological care to this potentially vulnerable patient group. Most of the studies on outcome of SE focused on the first months to a year after discharge, which might influence the QoL outcome. DRE patients in our study suffered for two decades from epilepsy, which likely explains some of the deterioration in QoL.

\section{Limitations of the Study}

Despite a careful design and strong efforts to gather follow-up data, this study has certain limitations. Direct comparison to other studies is difficult because of different healthcare settings, differences in etiology between different regions, age considerations (children are not included in our study), and varying treatment approaches. Definition of RSE might differ among studies with varying amount of drugs or time passed to define an SE as being refractory.

Due to the study design, which implies a questionnaire that was filled out by patients or their families, we cannot exclude a misunderstanding sometimes leading to incorrect answers. Furthermore, results of this survey are probably biased by selection due to the SE-associated mortality (overall 18.8\%) and morbidity that were also described in other studies (30).
Morbidity and mortality after discharge might explain the low responder rate of $15 \%$, and mortality at discharge and during follow-up might be the main confounder in our study. The average in-hospital mortality in our SE cohort is 5.8\% for nonRSE and 20.1\% for RSE and SRSE (1) and matches nationwide evaluations of mortality in SE (3). We have to assume that participating patients were able to write or communicate with their relatives to complete the questionnaire. Adults who depend on help of their family members, who live in a nursing home, or who suffer a severe disability might be underrepresented in this evaluation. As we used patient questionnaires to collect data regarding resource utilization, the possibility of incomplete patient recall in some of the categories cannot be excluded and could have resulted in an underestimation of resource use. Another limitation of the study is the relatively short evaluation period of 3 months, which could have led to large variability in estimates.

\section{CONCLUSION}

Patients after SE show substantial impairments in their QoL and daily life activities. However, QoL is comparable to patients with DRE, despite more SE patients being affected by neurological deficits. Further studies and treatment evaluations are warranted to answer questions on the outcome of SE patients in the future, especially if new treatment strategies might improve initial outcome and reduce in-hospital mortality. In the long term, patients with RSE and SRSE might have a favorable outcome regarding QoL and neurological functions compared to patients with a non-refractory course. This underlines the need for efficient therapeutic options in these challenging situations.

\section{ETHICS STATEMENT}

We confirm that we have read the Frontiers in Neurology position on ethics and procedures and confirm that this report is consistent with these guidelines.

\section{AUTHOR CONTRIBUTIONS}

LMK and AS generated the research idea, study design, and concept. LMK, FP, and AS acquired the data. LMK and AS analyzed the data and drafted the work. LMK, SK, FP, FR, and AS made critical revisions for important intellectual content and interpreted the data. LMK and AS wrote the manuscript. LMK, SK, FP, FR, and AS approved the final manuscript.

\section{ACKNOWLEDGMENTS}

We are grateful to all of our colleagues and the staff at the study centers in Frankfurt, Greifswald, and Marburg for their assistance in conducting this study. This study was conceptually supported by "Epilepsie-Förderverein Hessen e.V." and by an unrestricted grant from UCB Pharma, Monheim. The funding sources had no role in the study design, data collection, data analysis, data interpretation, or writing of the manuscript. 


\section{REFERENCES}

1. Kortland LM, Alfter A, Bahr O, Carl B, Dodel R, Freiman TM, et al. Costs and cost-driving factors for acute treatment of adults with status epilepticus: a multicenter cohort study from Germany. Epilepsia (2016) 57:2056-66. doi:10.1111/epi.13584

2. Kortland LM, Knake S, Rosenow F, Strzelczyk A. Cost of status epilepticus: a systematic review. Seizure (2015) 24:17-20. doi:10.1016/j.seizure.2014.11.003

3. Strzelczyk A, Ansorge S, Hapfelmeier J, Bonthapally V, Erder MH, Rosenow F. Costs, length of stay, and mortality of super-refractory status epilepticus: a population-based study from Germany. Epilepsia (2017) 58:1533-41. doi:10.1111/epi.13837

4. Ferlisi M, Shorvon S. The outcome of therapies in refractory and super-refractory convulsive status epilepticus and recommendations for therapy. Brain (2012) 135:2314-28. doi:10.1093/brain/aws091

5. Hocker SE, Britton JW, Mandrekar JN, Wijdicks EF, Rabinstein AA. Predictors of outcome in refractory status epilepticus. JAMA Neurol (2013) 70:72-7. doi:10.1001/jamaneurol.2013.578

6. Sutter R, Kaplan PW, Ruegg S. Outcome predictors for status epilepticus what really counts. Nat Rev Neurol (2013) 9:525-34. doi:10.1038/nrneurol. 2013.154

7. Sutter R, Marsch S, Fuhr P, Kaplan PW, Ruegg S. Anesthetic drugs in status epilepticus: risk or rescue? A 6-year cohort study. Neurology (2014) 82:656-64. doi:10.1212/WNL.0000000000000009

8. Kerr C, Nixon A, Angalakuditi M. The impact of epilepsy on children and adult patients' lives: development of a conceptual model from qualitative literature. Seizure (2011) 20:764-74. doi:10.1016/j.seizure.2011.07.007

9. Taylor RS, Sander JW, Taylor RJ, Baker GA. Predictors of health-related quality of life and costs in adults with epilepsy: a systematic review. Epilepsia (2011) 52:2168-80. doi:10.1111/j.1528-1167.2011.03213.x

10. Mula M, Cock HR. More than seizures: improving the lives of people with refractory epilepsy. Eur J Neurol (2015) 22:24-30. doi:10.1111/ene.12603

11. Kwon OY, Park SP. Depression and anxiety in people with epilepsy. J Clin Neurol (2014) 10:175-88. doi:10.3988/jcn.2014.10.3.175

12. von Elm E, Altman DG, Egger M, Pocock SJ, Gotzsche PC, Vandenbroucke JP, et al. Strengthening the Reporting of Observational Studies in Epidemiology (STROBE) statement: guidelines for reporting observational studies. BMJ (2007) 335:806-8. doi:10.1136/bmj.39335.541782.AD

13. Hamer HM, Spottke A, Aletsee C, Knake S, Reis J, Strzelczyk A, et al. Direct and indirect costs of refractory epilepsy in a tertiary epilepsy center in Germany. Epilepsia (2006) 47:2165-72. doi:10.1111/j.1528-1167.2006.00889.x

14. Strzelczyk A, Nickolay T, Bauer S, Haag A, Knake S, Oertel WH, et al. Evaluation of health-care utilization among adult patients with epilepsy in Germany. Epilepsy Behav (2012) 23:451-7. doi:10.1016/j.yebeh.2012.01.021

15. Trinka E, Cock H, Hesdorffer D, Rossetti AO, Scheffer IE, Shinnar S, et al. A definition and classification of status epilepticus - report of the ILAE task force on classification of status epilepticus. Epilepsia (2015) 56:1515-23. doi:10.1111/epi.13121

16. Fisher RS, Cross JH, French JA, Higurashi N, Hirsch E, Jansen FE, et al. Operational classification of seizure types by the International League Against Epilepsy: position paper of the ILAE commission for classification and terminology. Epilepsia (2017) 58:522-30. doi:10.1111/epi.13670

17. Shorvon S, Ferlisi M. The treatment of super-refractory status epilepticus: a critical review of available therapies and a clinical treatment protocol. Brain (2011) 134:2802-18. doi:10.1093/brain/awr215

18. Betjemann JP, Lowenstein DH. Status epilepticus in adults. Lancet Neurol (2015) 14:615-24. doi:10.1016/S1474-4422(15)00042-3

19. Beghi E, Carpio A, Forsgren L, Hesdorffer DC, Malmgren K, Sander JW, et al. Recommendation for a definition of acute symptomatic seizure. Epilepsia (2010) 51:671-5. doi:10.1111/j.1528-1167.2009.02285.x

20. Fisher RS, Acevedo C, Arzimanoglou A, Bogacz A, Cross JH, Elger CE, et al. ILAE official report: a practical clinical definition of epilepsy. Epilepsia (2014) 55:475-82. doi:10.1111/epi.12550

21. May TW, Pfafflin M, Cramer JA. Psychometric properties of the German translation of the QOLIE-31. Epilepsy Behav (2001) 2:106-14. doi:10.1006/ ebeh.2001.0170

22. Metternich B, Wagner K, Buschmann F, Anger R, Schulze-Bonhage A. Validation of a German version of the neurological disorders depression inventory for epilepsy (NDDI-E). Epilepsy Behav (2012) 25:485-8. doi:10.1016/ j.yebeh.2012.10.004

23. Aldenkamp AP, van Meel HF, Baker GA, Brooks J, Hendriks MP. The A-B neuropsychological assessment schedule (ABNAS): the relationship between patient-perceived drug related cognitive impairment and results of neuropsychological tests. Seizure (2002) 11:231-7. doi:10.1053/seiz.2002.0672

24. Panelli RJ, Kilpatrick C, Moore SM, Matkovic Z, D’Souza WJ, O’Brien TJ. The Liverpool adverse events profile: relation to AED use and mood. Epilepsia (2007) 48:456-63. doi:10.1111/j.1528-1167.2006.00956.x

25. EuroQol Group. EuroQol - a new facility for the measurement of health-related quality of life. Health Policy (1990) 16:199-208. doi:10.1016/ 0168-8510(90)90421-9

26. Banks JL, Marotta CA. Outcomes validity and reliability of the modified Rankin scale: implications for stroke clinical trials: a literature review and synthesis. Stroke (2007) 38:1091-6. doi:10.1161/01.STR.0000258355.23810.c6

27. Noda AH, Hermsen A, Berkenfeld R, Dennig D, Endrass G, Kaltofen J, et al. Evaluation of costs of epilepsy using an electronic practice management software in Germany. Seizure (2015) 26:49-55. doi:10.1016/j.seizure.2015.01.010

28. Strzelczyk A, Bergmann A, Biermann V, Braune S, Dieterle L, Forth B, et al. Neurologist adherence to clinical practice guidelines and costs in patients with newly diagnosed and chronic epilepsy in Germany. Epilepsy Behav (2016) 64:75-82. doi:10.1016/j.yebeh.2016.07.037

29. Lai A, Outin HD, Jabot J, Megarbane B, Gaudry S, Coudroy R, et al. Functional outcome of prolonged refractory status epilepticus. Crit Care (2015) 19:199. doi:10.1186/s13054-015-0914-9

30. Ferlisi M, Hocker S, Grade M, Trinka E, Shorvon S; International Steering Committee of the StEp A. Preliminary results of the global audit of treatment of refractory status epilepticus. Epilepsy Behav (2015) 49:318-24. doi:10.1016/j.yebeh.2015.04.010

31. Jayalakshmi S, Ruikar D, Vooturi S, Alladi S, Sahu S, Kaul S, et al. Determinants and predictors of outcome in super refractory status epilepticus - a developing country perspective. Epilepsy Res (2014) 108:1609-17. doi:10.1016/j. eplepsyres.2014.08.010

32. Elsharkawy AE, Thorbecke R, Ebner A, May TW. Determinants of quality of life in patients with refractory focal epilepsy who were not eligible for surgery or who rejected surgery. Epilepsy Behav (2012) 24:249-55. doi:10.1016/j. yebeh.2012.03.012

33. Gilliam F. Optimizing health outcomes in active epilepsy. Neurology (2002) 58:S9-20. doi:10.1212/WNL.58.8_suppl_5.S9

34. Zhao Y, Wu H, Li J, Dong Y, Liang J, Zhu J, et al. Quality of life and related factors in adult patients with epilepsy in China. Epilepsy Behav (2011) 22:376-9. doi:10.1016/j.yebeh.2011.07.025

35. Ferro MA, Camfield CS, Levin SD, Smith ML, Wiebe S, Zou G, et al. Trajectories of health-related quality of life in children with epilepsy: a cohort study. Epilepsia (2013) 54:1889-97. doi:10.1111/epi.12388

Conflict of Interest Statement: LMK reports personal fees from Desitin Arzneimittel. SK reports personal fees from Desitin Arzneimittel and UCB Pharma. FP reports industry-funded travel with support of Desitin Arzneimittel, Eisai, and UCB Pharma obtained honoraria for speaking engagements from Desitin Arzneimittel, Eisai, and UCB Pharma, was part of a speaker's bureau of Desitin Arzneimittel, Eisai, and UCB Pharma. FR reports grants and personal fees from Eisai, UCB Pharma, Desitin Arzneimittel, Novartis, Medtronic, Cerbomed, Sandoz, Shire, and the VfA (Verband der Forschenden Arzneimittelhersteller) and grants from European Union and Deutsche Forschungsgemeinschaft. AS reports grants and personal fees from Bayer HealthCare, Boehringer Ingelheim, Desitin Arzneimittel, Eisai, LivaNova, Pfizer, Sage Therapeutics, UCB Pharma, and Zogenix.

The reviewer FW and handling editor declared their shared affiliation.

Copyright (c) 2017 Kortland, Knake, von Podewils, Rosenow and Strzelczyk. This is an open-access article distributed under the terms of the Creative Commons Attribution License (CC BY). The use, distribution or reproduction in other forums is permitted, provided the original author(s) or licensor are credited and that the original publication in this journal is cited, in accordance with accepted academic practice. No use, distribution or reproduction is permitted which does not comply with these terms. 